OPEN ACCESS

Edited by:

Philipp Taussky,

University of Utah, United States

Reviewed by:

Manish Singh Sharma,

Mayo Clinic Health System,

United States

Gregory Fabrice Jost,

University of Basel, Switzerland

*Correspondence:

Nicoleta Stoicea

nicoleta.stoicea@osumc.edu

Specialty section:

This article was submitted

to Neurosurgery,

a section of the journal

Frontiers in Surgery

Received: 20 March 2017 Accepted: 08 June 2017

Published: 26 June 2017

Citation:

Mendel E, Stoicea N, Rao R, Niermeyer W, Revilla S, Cluse M,

Sandhu G, Todaro GJ and

Bergese SD (2017) Revisiting

Postoperative Vision Loss following Non-Ocular Surgery: A Short Review of Etiology and Legal Considerations.

Front. Surg. 4:34.

doi: 10.3389/fsurg.2017.00034

\section{Revisiting Postoperative Vision Loss following Non-Ocular Surgery: A Short Review of Etiology and Legal Considerations}

\author{
Ehud Mendel', Nicoleta Stoicea ${ }^{2 *}$, Rahul Rao ${ }^{3}$, Weston Niermeyer ${ }^{4}$, Stephen Revilla ${ }^{4}$, \\ Marcus Cluse ${ }^{4}$, Gurneet Sandhu', Gerald J. Todaro ${ }^{5}$ and Sergio D. Bergese ${ }^{1,2}$ \\ 'Department of Neurological Surgery, The Ohio State University Wexner Medical Center, Columbus, OH, United States, \\ ${ }^{2}$ Department of Anesthesiology, The Ohio State University Wexner Medical Center, Columbus, OH, United States, ${ }^{3}$ West \\ Virginia School of Osteopathic Medicine, Lewisburg, WW, United States, ${ }^{4}$ College of Medicine, The Ohio \\ State University, Columbus, $\mathrm{OH}$, United States, ${ }^{5}$ Arnold Todaro \& Welch, Columbus, OH, United States
}

Postoperative vision loss (POVL) following non-ocular surgery is a serious complication where the causes are not fully understood. Studies have identified several causes of POVL as well as risk factors and prevention strategies. POVL research is made difficult by the fact that cases are often subject to malpractice claims, resulting in a lack of public access to case reports. This literature review was conducted in order to identify legal issues as a major barrier to studying POVL and address how this affects current knowledge. Informed consent provides an opportunity to overcome legal challenges by reducing malpractice litigation through educating the patient on this outcome. Providing pertinent information regarding POVL during the informed consent process has potential to reduce malpractice claims and increase available clinical information.

Keywords: ischemic optic neuropathy, malpractice, non-ocular surgery with vision loss, postoperative vision loss, neurosurgery

\section{INTRODUCTION}

Postoperative vision loss (POVL) during non-ocular procedures is a devastating complication following surgery under general anesthesia. There is significant variation in the reported incidence of POVL ranging from 0.056 to $1.3 \%$ (1). Surgical procedures posing the highest risk for POVL are cardiac (incidence $=0.09 \%$ ) and spinal surgeries (incidence as high as $0.2 \%)(2,3)$. Etiologies of POVL include ischemic optic neuropathy (ION), central retinal artery occlusion (CRAO), cortical blindness (CB), and corneal abrasion (CA) (4). Strong evidence indicates an increasing incidence of POVL in part due to the rising number of spinal fusion operations (500\% from 1993 through 2004) (5). Risk factors for these conditions have been identified; however, the mechanisms are not yet fully understood $(4,6-8)$. Male gender, prone position during surgery, hypotension, prolonged procedures, longer anesthesia duration, and decreased use of colloids are associated with POVL (9-13). Certain modifiable risk factors are obesity, cardiovascular disease, hyperlipidemia, diabetes mellitus, and smoking $(4,6,7,14)$. We intend to review the medicolegal barriers preventing access to current POVL information and subsequently hindering the advancement of knowledge on this topic (Figure 1). 


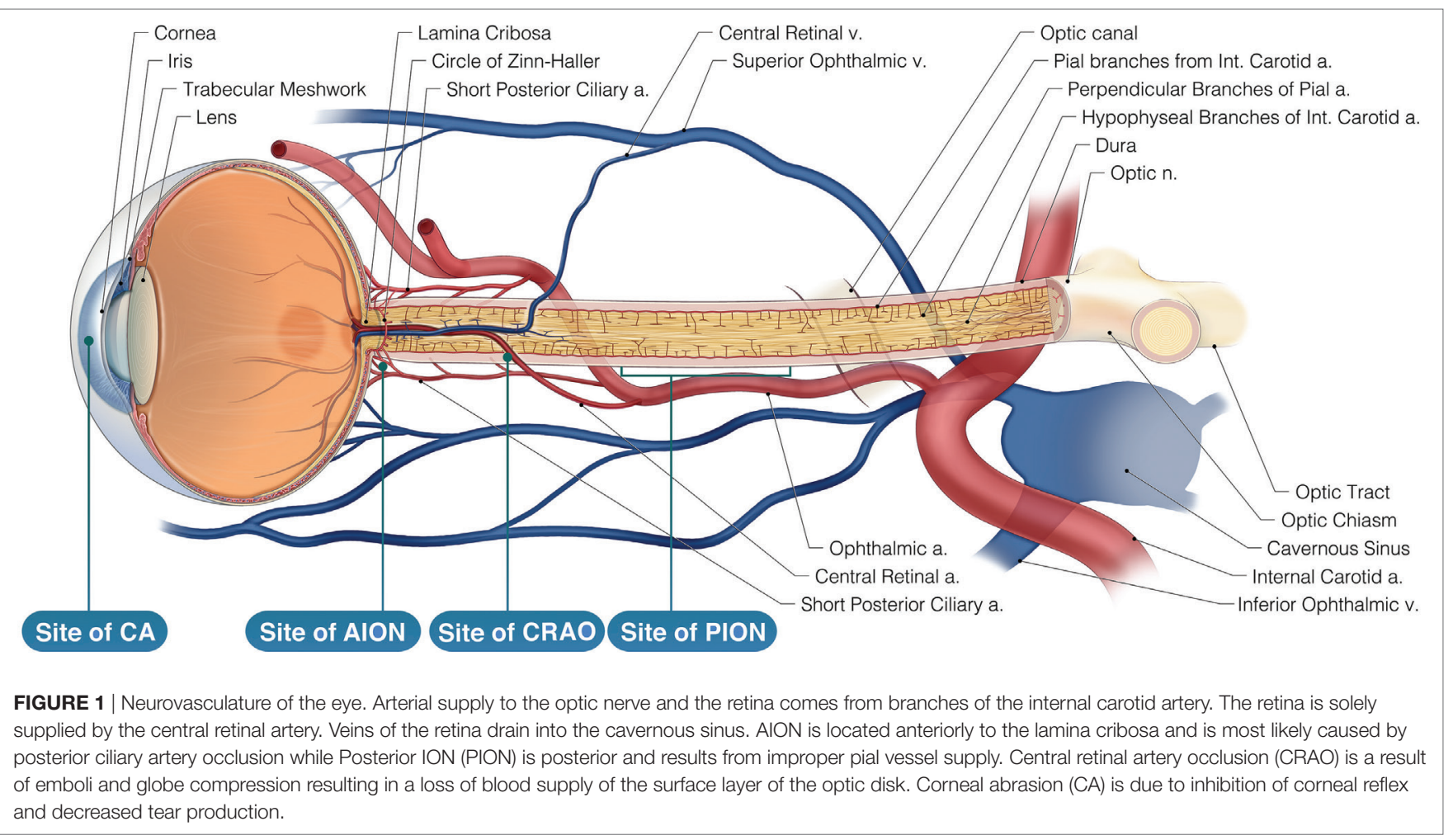

\section{LITERATURE SEARCH METHODOLOGY}

A literature search was conducted via PubMed, Google Scholar, and American Society of Anesthesiologists (ASA) Closed Claims Databases using the following keywords: postoperative vision loss, ischemic optic neuropathy, malpractice, and nonocular surgery with vision loss. Articles within the search criteria included case reports, registry reports, reviews, randomized trials, cohort studies, newsletters, and case control studies published since 2000. Non-English literature was excluded from the search.

\section{RESULTS/DISCUSSION}

Vision loss caused by non-ocular surgery poses severe implications for a patient's quality of life. POVL is frequently involved in malpractice claims complicating the study of its mechanisms and assessment of causative factors (15). Until legal action is resolved, reporting POVL cases can be delayed up to 7 years (16). Although there is no mandated reporting system for POVL, the ASA Closed Claims Project registry was created in 1999 to facilitate physicians' access to an up-to-date database of vision loss cases after non-ophthalmic surgery (17). In 2014, the project database contained 10,093 claims of which 7,351 were surgical anesthesia claims (18). Non-ocular POVL cases are submitted to the registry without patient, provider, or institutional identifiers in order to protect confidentiality and encourage hospitals to report events of POVL with minimal legal ramifications (19). ASA members are able to request access to search the database; however, such requests are limited to "simple analysis of narrowly defined topics." (17) Cases submitted to the registry remain protected from public access (17). In 2014, the Agency for Healthcare Research and Quality reported that plaintiff attorneys made numerous requests for release of the POVL registry data to the public. The registry denied public release of the information in accordance with board-approved confidentiality procedures (19). The rarity of this complication and the complexity of reported cases have resulted in a paucity of research on POVL. Because current data are limited, there is no well-established standard of care. The ASA Perioperative Visual Loss Task Force developed a practice advisory focused on perioperative management for patients identified to be at high risk (20). Without a complete understanding of this serious adverse event, advances in establishing POVL management guidelines are hindered.

Research into the underlying pathophysiology of more common causes of POVL, such as CA, has led to more effective prevention strategies and fewer malpractice claims $(1,21,22)$ (Table 1).

\section{Corneal Abrasion}

Corneal abrasion while under general anesthesia is a result of decreased corneal protection through inhibition of the corneal reflex and decreased tear production (22). Longer procedures, as well as prone or lateral positioning during surgery, are shown to increase the risk of CA (21). Many institutions have developed prevention strategies for CA (18). Treatment of CA usually involves administration of artificial tears and antibiotic ointment (23). 
TABLE 1 | Summary of identified causes of postoperative vision loss (POVL) and malpractice claims.

\begin{tabular}{|c|c|c|c|c|c|c|}
\hline $\begin{array}{l}\text { Identified } \\
\text { cause of } \\
\text { POVL }\end{array}$ & Pathophysiology & Clinical presentation & Incidence range & $\begin{array}{l}\text { Postoperative } \\
\text { eye injury } \\
\text { malpractice } \\
\text { claim incidence } \\
\text { (1980-2011) }\end{array}$ & $\begin{array}{l}\text { Permanent } \\
\text { eye injuries } \\
(1980-2011)\end{array}$ & $\begin{array}{l}\text { Median } \\
\text { claim } \\
\text { payment } \\
(1980-2011)\end{array}$ \\
\hline $\begin{array}{l}\text { Corneal } \\
\text { abrasion }\end{array}$ & $\begin{array}{l}\text { Decreased corneal } \\
\text { protection through } \\
\text { inhibition of corneal reflex } \\
\text { and decreased tear } \\
\text { production (21) }\end{array}$ & $\begin{array}{l}\text { Complaints of blurry vision, tearing, } \\
\text { redness, photophobia, foreign body } \\
\text { sensation (23) }\end{array}$ & $\begin{array}{l}0.17-44 \% \text { during } \\
\text { the perioperative } \\
\text { period ( } 23)\end{array}$ & $\begin{array}{l}31 \%(1980-1994) \\
18 \%(1995-2011)(18)\end{array}$ & & \\
\hline \multirow[t]{2}{*}{$\begin{array}{l}\text { Ischemic optic } \\
\text { neuropathy }\end{array}$} & \multirow[t]{2}{*}{$\begin{array}{l}\text { Not well understood; } \\
\text { proposed mechanisms } \\
\text { include increased } \\
\text { intraocular pressure and } \\
\text { ophthalmic vein congestion } \\
\text { (25) }\end{array}$} & $\begin{array}{l}\text { AION: painless and progressive } \\
\text { deterioration of vision, optic } \\
\text { disk edema which resolves } \\
\text { spontaneously in } 7.9-11.4 \text { weeks }\end{array}$ & $\begin{array}{l}89 \% \text { of POVL } \\
\text { occurring from } \\
\text { spine surgery; } \\
\text { Posterior ION } \\
\text { (PION) accounts } \\
\text { for } 60 \% \text { of these } \\
\text { cases (26) }\end{array}$ & $\begin{array}{l}\text { Optic nerve } \\
\text { injuries: } \\
5 \%(1980-1994)\end{array}$ & $\begin{array}{c}49 \% \\
(1980-1994)\end{array}$ & $\begin{array}{c}\$ 128,100 \\
(1980-1994)\end{array}$ \\
\hline & & $\begin{array}{l}\text { PION: acute painless visual loss in } \\
\text { one or both eyes that can progress } \\
\text { to complete blindness (14) }\end{array}$ & & \multirow[t]{2}{*}{$\begin{array}{c}38 \%(1995-2011) \\
(24)\end{array}$} & \multirow[t]{3}{*}{$\begin{array}{c}73 \% \\
(1995-2011) \\
(24)\end{array}$} & \multirow[t]{3}{*}{$\begin{array}{c}\$ 424,750 \\
(1995-2011) \\
(24)\end{array}$} \\
\hline $\begin{array}{l}\text { Central } \\
\text { retinal artery } \\
\text { occlusion }\end{array}$ & $\begin{array}{l}\text { Emboli and direct } \\
\text { pressure on the globe (9) }\end{array}$ & $\begin{array}{l}\text { Typically manifests unilaterally with } \\
\text { "cattle tracking" of the arterioles } \\
\text { with a "cherry-red" spot visible } \\
\text { during fundoscopic exam (27) }\end{array}$ & $\begin{array}{l}11 \% \text { of spine } \\
\text { surgeries (26) }\end{array}$ & & & \\
\hline $\begin{array}{l}\text { Cortical } \\
\text { blindness (CB) }\end{array}$ & $\begin{array}{l}\text { Ischemia or extreme } \\
\text { hypoperfusion of the } \\
\text { occipital lobes ( } 7 \text { ) }\end{array}$ & $\begin{array}{l}\text { Deteriorating vision that results in } \\
\text { partial or bilateral POVL (7) }\end{array}$ & $\begin{array}{l}0.0038 \% \text { of POVL } \\
\text { cases due to } \\
\text { CB (28) }\end{array}$ & - & & \\
\hline
\end{tabular}

No intervention is completely effective in protection of CA during surgery, but eyelid taping is the single best used protective method. Proper placement of eyelid protection has been shown to decrease the risk of CA (21). CA claims from 1990 or later received a median compensation of $\$ 12,000$. The registry reports a decrease in the incidence of claims from 31\% in 1980-1994 to $18 \%$ in 1995-2011, most of them being associated with general anesthesia (18). The reduction in CA malpractice claims from 1980 to 2011 is likely reflective of the effective prevention measures taken by anesthesiologists prior to surgery.

Permanent eye injury following non-ocular surgery, a less understood complication with severe patient outcomes, is a vital area for further research often delayed by malpractice claims (24). Lee et al. reported that permanent eye injury claims and optic nerve damage claims increased from 1980 to 2011 with the majority of closed claims involving spinal surgeries (24). Permanent injury following surgery increased from 49 to $73 \%$ of total reported eye injury cases. The median payment made for permanent vision loss malpractice claims escalated from $\$ 128,100$ (1980-1994) to $\$ 424,750$ (1995-2011), when adjusted for 2013 inflation (24).

\section{Ischemic Optic Neuropathy}

Ischemic optic neuropathy is the most common cause of permanent POVL after non-ocular surgery $(26,29)$. Prone and Trendelenburg positioning during surgery can increase intraocular pressure (IOP) and cause ophthalmic vein congestion leading to ION, and in some cases, permanent POVL $(25,29)$. The ASA Postoperative Visual Loss Registry reported that $89 \%$ of perioperative vision loss in spine surgery is due to ION, with posterior ION (PION) accounting for $60 \%$ of cases (26).

A recent article published by Rubin et al. studied trends in ION incidence in spinal fusion using a large nationwide hospital database from 1998 to 2012 and concluded that perioperative ION in spinal fusion decreased by 2.7 -fold. Aging, obesity, male gender, and transfusions were significantly associated with ION (30).

Posterior ION is most commonly associated with operations performed in the prone position and of longer duration, and typically presents as painless loss of vision when the patient awakens from anesthesia (29). While anemia and hypotension are observed in these patients, the exact mechanism by which the ischemia occurs remains unclear. Although predisposing factors have been identified, no single causative mechanism for ION can fully explain the etiology under various surgical circumstances (3). Quraishi et al. published a case where improved vision after surgery in a patient diagnosed with PION was achieved by managing hemoglobin, hematocrit, and systolic blood pressure in order to adequately maintain ocular perfusion (31). Hassani et al. demonstrated that administering recombinant human erythropoietin reversed the effects of PION following a $6 \mathrm{~h}$ procedure with significant blood loss (32). The ASA Task Force on Perioperative Visual Loss reports that no complete treatment guideline has been established. The recommendation is that consideration should be given to informing the patient of the "small" and "unpredictable risk" of POVL in high-risk cases and to employ preventative strategies (33). 
When the patient notices even slight changes in vision, a thorough physical exam should be performed as the viability of POVL treatment options tend to decline over time. Contractor and Hardman stated that all patients experiencing signs of POVL require urgent review by an ophthalmologist (34).

\section{Central Retinal Artery Occlusion}

Central retinal artery occlusion accounts for a small percentage of POVL cases, but is the second most common cause associated with spinal surgery (5). According to the ASA POVL registry, POVL in $11 \%$ of spine surgery cases is caused by CRAO $(3,26)$. CRAO is commonly associated with emboli and direct compression of the globe (9). Unlike PION, CRAO more commonly manifests unilaterally. Prone-positioned surgery increases the risk of CRAO due to external ocular compression produced by the weight of the head against the headrest $(5,15,33)$. CRAO is considered reversible if treated within $6 \mathrm{~h}$ (35). Treatments including vasodilators, ocular massage, and thrombolytic agents are able to improve visual deficits caused by CRAO, but their effects are poorly demonstrated in ION (22).

\section{Cortical Blindness}

Cortical blindness is known as the third major identified cause of POVL in non-ocular surgery. $\mathrm{CB}$ is a loss of vision caused by ischemia or extreme hypoperfusion of the occipital lobes. This can manifest as bilateral vision loss ranging from partial to complete (7). Most cases of $\mathrm{CB}$ are caused by spontaneous ischemic stroke $(32 \%)$, cardiac surgery $(20 \%)$, and cerebral angiography (12\%) (36).

Intraoperative factors, such as anesthetic duration, blood loss, position during surgery, and fluid administration, are equally important to consider. The ASA Practice Advisory states that patients should be positioned with their head at the same level or higher than the heart and maintained in a neutral forward position when possible in order to reduce IOP and prevent POVL from occurring (33). The ASA POVL Registry data collected between 1999 and 2012 shows that $94 \%$ of ION cases resulted from surgeries performed under general anesthesia for $6 \mathrm{~h}$ or longer. It has been suggested that procedures requiring prolonged anesthesia can be staged in order to reduce length of the surgery. If staging is to be used, the patient should be informed of the risk imposed by this type of procedure compared to prolonged anesthesia (33). Although these possible strategies have been suggested, there is no evidence to fully support their use in preventing ION (37).

Due to the different etiologies of POVL and the limited effectiveness of treatments, disclosure of information regarding POVL prior to surgery is appropriate to consider (38). One method to accomplish this disclosure is through informed consent. The case Salgo $v$ Stanford (1957) first used the term informed consent and ruled that informed consent should make known to patients all potential risks, benefits, and alternative treatments before undergoing surgical or anesthetic procedures (38-40). The court's decision states, "a physician violates his duty to his patient and subjects himself to liability if he withholds any facts ... necessary to form the basis of an intelligent consent by the patient to the proposed treatment" (40). Furthermore, the court concluded that physicians were permitted to use discretion in order to withhold facts based upon the patient's mental and emotional state (39). In the early 1970s, a new version of informed consent doctrine quickly became recognized "in one form or another in virtually every state." This doctrine dictated that, in addition to giving a patient the decision to consent to or refuse healthcare, a physician was required to provide the patient with all information that a "reasonably prudent person" would find "material" to making this decision (39). One survey published in 2011 determined that out of 437 patients undergoing spinal surgery at Mayo Clinic in Florida, $80 \%$ preferred full disclosure of the risks of POVL (38). During an Anesthesia Patient Safety Foundation conference, a consensus was reached regarding discussion of POVL due to ION during the informed consent process of patients considered to be at risk by anesthesiologists and surgeons (41). The informed consent process may further advise patients on occurrence of POVL, risk factors both modifiable and non-modifiable, and prevention strategies without eliminating the risk of developing POVL (41).

\section{CONCLUSION}

Patient-centered guidelines on discussing POVL occurrence, risk factors, and prevention strategies are essential. The rare incidence of POVL and the resulting paucity of publications account for the limited understanding of this complication. Bolstering the data available to physicians and researchers could facilitate better knowledge of POVL pathophysiology, risk factors, and contribute to the development of preemptive measures and treatment techniques to improve patient outcomes.

\section{AUTHOR CONTRIBUTIONS}

$\mathrm{RR}, \mathrm{WN}, \mathrm{SR}$, and MC conducted the literature search and participated in early drafting of the manuscript. EM, NS, SB, and GS participated in drafting of the article and provided critical review of the clinical information. GT provided insight and guidance for the legal sections of the manuscript. NS conducted the final revision of the manuscript. This project was performed under the guidance and oversight of SB.

\section{ACKNOWLEDGMENTS}

We thank Anthony Baker, Board-Certified Medical Illustrator, Senior Graphic Designer at The Ohio State University, Health Sciences Library Medical Visuals, for his assistance with the final version of the "Neurovasculature of the eye" diagram. We thank Rahul Rao, medical student, for his initial version of "Neurovasculature of the eye." 


\section{REFERENCES}

1. Kitaba A, Martin DP, Gopalakrishnan S, Tobias JD. Perioperative visual loss after nonocular surgery. J Anesth (2013) 27(6):919-26. doi:10.1007/ s00540-013-1648-y

2. Goni V, Tripathy SK, Goyal T, Tamuc T, Panda BB, Shashidhar BK. Cortical blindness following spinal surgery: very rare cause of perioperative vision loss. Asian Spine J (2012) 6(4):287-90. doi:10.4184/asj.2012.6.4.287

3. Nickels TJ, Manlapaz MR, Farag E. Perioperative visual loss after spine surgery. World J Orthop (2014) 5(2):100-6. doi:10.5312/wjo.v5.i2.100

4. De la Garza-Ramos R, Samdani AF, Sponseller PD, Ain MC, Miller NR, Shaffrey CI, et al. Visual loss after corrective surgery for pediatric scoliosis: incidence and risk factors from a nationwide database. Spine J (2016) 16(4):516-22. doi:10.1016/j.spinee.2015.12.031

5. Baig BN, Lubow M, Immesoette P, Bergese SD, Hamdy E, Mendel E. Vision loss after spinal surgery: review of the literature and recommendations. Neurosurg Focus (2007) 23(5):E15. doi:10.3171/FOC-07/11/15

6. Li A, Swinney C, Veeravagu A, Bhatti I, Ratliff J. Postoperative visual loss following lumbar spine surgery: a review of risk factors by diagnosis. World Neurosurg (2015) 84(6):2010-21. doi:10.1016/j.wneu.2015.08.030

7. Yu HD, Chou AH, Yang MW, Chang CJ. An analysis of perioperative eye injuries after nonocular surgery. Acta Anaesthesiol Taiwan (2010) 48(3):122-9. doi:10.1016/S1875-4597(10)60043-4

8. Uribe AA, Baig MN, Puente EG, Viloria A, Mendel E, Bergese SD. Current intraoperative devices to reduce visual loss after spine surgery. Neurosurg Focus (2012) 33(2):E14. doi:10.3171/2009.8.FOCUS09151

9. Lee J, Chin JH, Koh WU, Ro YJ, Yang HS. Unilateral postoperative visual loss in a patient undergoing hip arthroscopy in the supine position: a case report. Korean J Anesthesiol (2016) 69(2):197-9. doi:10.4097/kjae.2016.69.2.197

10. Mukherjee B, Alam MS. Acute visual loss with ophthalmoplegia after spinal surgery: report of a case and review of the literature. Indian J Ophthalmol (2014) 62(9):963-5. doi:10.4103/0301-4738.143951

11. Patel AV, Desai AK, Vala RH, Patel EM. Unilateral vision loss after prolonged prone position in spinal surgery. IJHSR (2015) 5(1):369-73.

12. Lee LA. Risk factors associated with ischemic optic neuropathy after spinal fusion surgery. Anesthesiology (2012) 116(1):15-24. doi:10.1097/ ALN.0b013e31823d012a

13. Roth S, Tung A, Ksiazek S. Visual loss in a prone-positioned spine surgery patient with the head on a foam headrest and goggles covering the eyes: an old complication with a new mechanism. Anesth Analg (2007) 105(5):1185-7. doi:10.1213/01.ane.0000264319.57758.55

14. Hayreh SS. Management of ischemic optic neuropathies. Indian J Ophthalmol (2011) 59(2):123. doi:10.4103/0301-4738.77024

15. Roth S, Barach P. Postoperative visual loss: still no answers - yet. Anesthesiology (2001) 95(3):575-7. doi:10.1097/00000542-200109000-00006

16. Molloy BL. Implications for postoperative visual loss: steep Trendelenburg position and effects on intraocular pressure. AANA J (2011) 79(2):115-21.

17. Postoperative Visual Loss Registry. Anesthesia Closed Claims Project. (2016). Available from: http://depts.washington.edu/asaccp/projects/postoperativevisual-loss-registry

18. Posner KL, Lee LA. Anesthesia malpractice claims associated with eye surgery and eye injury: highlights from the anesthesia closed claims project data request service. ASA Newsl (2014) 78(11):28-30.

19. Gliklich RE, Dreyer NA, Leavy MB, editors. Registries for Evaluating Patient Outcomes: A User's Guide. 3rd ed. Rockville, MD: Agency for Healthcare Research and Quality (US) (2014). Protecting Data: Confidentiality and Legal Concerns of Providers, Manufacturers, and Health Plans.

20. Newman NJ. Perioperative visual loss after nonocular surgeries. Am J Ophthalmol (2008) 145(4):604-10. doi:10.1016/j.ajo.2007.09.01

21. Grixti A, Sadri M, Watts MT. Corneal protection during general anesthesia for nonocular surgery. Ocul Surf (2013) 11(2):109-18. doi:10.1016/j. jtos.2012.10.003

22. Stevens G. Prone to blindness: answers to postoperative visual loss. Anesth Analg (2011) 12(1):11-2. doi:10.1213/ANE.0b013e3181fe772d

23. Segal KL, Fleischut PM, Kim C, Levine B, Faggiani SL, Banerjee S, et al. Evaluation and treatment of perioperative corneal abrasions. J Ophthalmol (2014) 2014:Article ID 901901. doi:10.1155/2014/901901
24. Lee L, Posner KL, Domino KB. Trends in injuries to the visual pathways and medicolegal payments from the closed claims project database. Anesthesiology (2013):A2058.

25. Farag E, Cheung C, Kurz A. Recent advances in understanding the causes of postoperative vision loss after spine surgery. J Anesth Clin Res (2012) 3:e105. doi:10.4172/2155-6148.1000e105

26. Lee LA, Roth S, Posner KL, Cheney FW, Caplan RA, Newman NJ, et al. The American Society of Anesthesiologists Postoperative Visual Loss Registry: analysis of 93 spine surgery cases with postoperative visual loss. Anesthesiology (2006) 105(4):652-9. doi:10.1097/00000542-200610000-00007

27. Varma DD, Cugati S, Lee AW, Chen CS. A review of central retinal artery occlusion: clinical presentation and management. Eye (2013) 27:688-97. doi:10.1038/eye.2013.25

28. Shen Y, Drum M, Roth S. The prevalence of perioperative visual loss in the United States: a 10-year study from 1996 to 2005 of spinal, orthopedic, cardiac, and general surgery. Anesth Analg (2009) 109(5):1534-45. doi:10.1213/ ane.0b013e3181b0500b

29. Kla KM, Lee LA. Perioperative visual loss. Best Pract Res Clin Anaesthesiol (2016) 30:69-77. doi:10.1016/j.bpa.2015/11/004

30. Rubin DS, Parakati I, Lee LA, Moss HE, Joslin CE, Roth S. Perioperative visual loss in spine fusion surgery: ischemic optic neuropathy in the United States from 1998 to 2012 in the nationwide inpatient sample. Anesthesiology (2016) 125(3):457-64. doi:10.1097/ALN.0000000000001211

31. Quraishi NA, Wolinsky JP, Gokaslan ZL. Transient bilateral post-operative visual loss in spinal surgery. Eur Spine J (2012) 21(4):495-8. doi:10.1007/ s00586-011-2117-7

32. Hassani V, Homaei MM, Shahbazi A, Zamani MM, Safari S, Nadi S, et al. Human erythropoietin effect in postoperative visual loss following spine surgery: a case report. Anesth Pain Med (2014) 4(2):e7291. doi:10.5812/aapm.7291

33. American Society of Anesthesiologists Task Force on Perioperative Visual Loss. Practice advisory for perioperative visual loss associated with spine surgery: an updated report by the American Society of Anesthesiologists Task Force on Perioperative Visual Loss. Anesthesiology (2012) 116(2):274. doi:10.1097/ALN.0b013e31823c104d

34. Contractor S, Hardman JG. Injury during anaesthesia. Contin Educ Anaesth Crit Care Pain (2006) 6(2):67-70. doi:10.1093/bjaceaccp/mkl004

35. Cugati S, Varma DD, Chen CS, Lee AW. Treatment options for central retinal artery occlusion. Curr Treat Options Neurol (2013) 15(1):63-77. doi:10.1007/ s11940-012-0202-9

36. Aldrich MS, Alessi AG, Beck RW, Gilman S. Cortical blindness: etiology, diagnosis, and prognosis. Ann Neurol (1987) 21(2):149-58. doi:10.1002/ ana.410210207

37. Roth S. Perioperative visual loss: what do we know, what can we do? Br J Anaesth (2009) 103(Suppl 1):i31-40. doi:10.1093/bja/aep295

38. Corda DM, Dexter F, Pasternak JJ, Trentman TL, Brull SJ, Nottmeier EW. Patients' perspective on full disclosure and informed consent regarding postoperative visual loss associated with spinal surgery in the prone position. Mayo Clin Proc (2011) 86(9):865-8. doi:10.4065/mcp.2011.0279

39. Dolgin JL. The legal development of the informed consent doctrine: past and present. Camb Q Healthc Ethics (2010) 19(01):97-109. doi:10.1017/ S0963180109990284

40. Salgo v. Leland Stanford etc. Bd. Trustees P. 2d. (Vol. 317). (1957). 170 p. Cal: Court of Appeals, 1st Appellate Dist, 1st Div.

41. Lee LA, Stoelting RK. APSF-sponsored conference on perioperative visual loss develops consensus conclusions. APSF Newslett (2013) 27(3):52.

Conflict of Interest Statement: The authors declare that the research was conducted in the absence of any commercial or financial relationships that could be construed as a potential conflict of interest.

Copyright (C) 2017 Mendel, Stoicea, Rao, Niermeyer, Revilla, Cluse, Sandhu, Todaro and Bergese. This is an open-access article distributed under the terms of the Creative Commons Attribution License (CC BY). The use, distribution or reproduction in other forums is permitted, provided the original author(s) or licensor are credited and that the original publication in this journal is cited, in accordance with accepted academic practice. No use, distribution or reproduction is permitted which does not comply with these terms. 